\title{
QUEIMA DE PNEUS INSERVÍVEIS EM FORNOS DE CLÍNQUER
}

\author{
Luciane Pimentel Costa Monteiro ${ }^{1}$ \\ Fernando Benedicto Mainier ${ }^{2}$
}

\begin{abstract}
Resumo: A queima de resíduos industriais nos fornos de clínquer tem sido tema de discussão em âmbito nacional e internacional por estar relacionada às implicações no que diz respeito às emissões atmosféricas e à qualidade do cimento produzido. As unidades de cimento estão se confrontando com os problemas de sustentabilidade, ao terem que garantir não somente os suprimentos de matérias-primas e insumos energéticos, como de cumprir normas e padrões. Várias são as pressões tecnológicas para que se estude o impacto ambiental de contaminantes desses resíduos na produção de cimentos com especificação ambiental adequada. Sabe-se que os resíduos industriais são incinerados em função de seu poder calorífico, mas, geralmente, aumentam sobremaneira o volume de cinzas. Além disso, os metais contaminantes, presentes nos resíduos e, com baixo ponto de ebulição, tendem a poluir o ar do entorno das fábricas, pois se transformam em vapor durante o processo. O principal objetivo desse trabalho é alertar para a possibilidade de contaminações, sejam de cimentos nacionais ou importados, provenientes das rotas de fabricação, muitas das vezes desconhecidas, onde os combustíveis alternativos como os pneus inservíveis, podem ser fontes permanentes não declaradas de contaminações ambientais e do próprio cimento produzido.
\end{abstract}

Palavras-chave: cimenteira; pneus inservíveis; contaminações.

Abstract: The industrial residues incineration on clincker furnaces has been discussed in the entire world, because to the environmental problems caused on the atmosphere and the quality of the produced cement. This promotes on a lot of sustainability problems in the cement industries because they have to guarantee the raw and fuels as well as to obey the environmental legislation. Some society segments hope the necessary study of the environment impact of the contaminants residues in the cement production. The ash volume increases with the residues incineration and the metals contaminants present in the residues are a great source of environmental contaminations. The principal objective of this paper is to alert to the contaminations possibilities related to the residues burned in the clincker furnaces. One example is the used tires, which can be permanents sources of environmental contaminations and of the own produced cement.

Key-words: cement industry; used tires; contaminations.

\footnotetext{
${ }^{1}$ UFF - Departamento de engenharia Química e Petróleo, e-mail: lucianemonteiro@predialnet.com.br

${ }^{2}$ UFF - Departamento de Engenharia Química e Petróleo, e-mail: mainier@nitnet.com.br

ENGEVISTA, v. 10, n. 1, p. 52-58, junho 2008
} 


\section{INTRODUÇÃO}

A construção civil e a fabricação de artefatos de cimento têm sido responsáveis pela produção nacional de cimento, atualmente, com mais de 35 milhões de toneladas.

Muitas plantas foram ampliadas e modernizadas, além de outras instaladas. Isso gerou uma concentração de capital nas jazidas de calcário e fábricas de cimento, tornando relevante o peso dos proprietários e sócios estrangeiros dessas unidades. Acrescido a isso, houve a modernização nos processos de fabricação empregados, redução de custos, principalmente, no que concerne ao combustível utilizado e, algum investimento na redução da emissão de particulados (pó), que é a poluição visual observada pela sociedade.

Resíduos industriais de natureza diversificada têm contribuído como fontes de substituição de combustível em fornos rotativos de produção de clínquer das unidades de fabricação de cimento, visando uma recuperação de recursos ao invés de uma simples operação de destruição desses resíduos.

Essa atividade pode ser interessante no momento em que não cause impactos ambientais, não afete as condições de segurança e saúde pública das populações vizinhas, não cause prejuízo aos equipamentos da unidade e finalmente não contamine o clínquer/cimento produzido.

As unidades de cimento estão se confrontando com os problemas de sustentabilidade, ao terem que garantir não somente os suprimentos de matériasprimas e insumos energéticos, como de cumprir normas e padrões.

$\mathrm{Na}$ visão crítica, as cimenteiras brasileiras ou estrangeiras, nem sempre contemplam com abrangência os problemas relacionados à tecnologia, aos trabalhadores da indústria do cimento, aos impactos ambientais decorrentes e, provavelmente, não sofrem fiscalização técnico crítica permanente.
Um resíduo, extremamente cogitado para queima em fornos de clínquer, é o pneu inservível, como forma de solucionar os problemas ambientais que esses resíduos causam por si só (ocupação exagerada de espaço físico para sua deposição, não se degeneram fácil e rapidamente, atraem larvas de insetos nocivos à saúde), entretanto, sua queima libera para a atmosfera $\mathrm{SO}_{\mathrm{x}}$ e $\mathrm{CO}_{2}$, além de outros componentes químicos provenientes de sua composição.

Mesmo assim, é sugerido o seu emprego como uma alternativa para queima nos fornos das cimenteiras, visando suprir seu consumo energético. A tendência, é que as cimenteiras venham a se deparar cada vez mais com os problemas decorrentes das alterações ambientais originárias do processo de produção, a partir da opção por renováveis, não renováveis $\mathrm{e}$, de resíduos industriais de outros processos.

Assim, começam a enfrentar os problemas decorrentes do potencial tóxico e riscos ambientais de seus processos na emissão de seus efluentes e, também, na qualidade do cimento produzido.

A função dos órgãos fiscalizadores é monitorar no sentido de resguardar, esclarecer, aclarar e advertir a população dos efeitos danosos dos materiais inadequados e, sobretudo, daqueles nocivos à saúde.

Seja por parte do governo, ao assumir o monitoramento da observância de prescrições legais e normas técnicas, além de buscar o controle da propaganda enganosa na mídia; sejam por parte dos engenheiros de processos industriais, ao abrir as portas desse compartimento da ciência e colocá-lo à disposição do público, via divulgação em eventos, veículos de massa e publicações científicas; seja por parte dos profissionais da área de saúde, ao advertir sobre os problemas imputados pelo desaviso; seja por parte de educadores, ao ajudar não apenas na socialização, mas na construção de um 
conhecimento consumível no cotidiano, fazendo do homem comum o fiscal de sua própria defesa, cada vez mais, autônoma e livre de qualquer tutela assistencialista do Estado.

O principal objetivo desse trabalho é alertar para a possibilidade de contaminações, sejam de cimentos nacionais ou importados, provenientes das rotas de fabricação, muitas das vezes desconhecidas, onde os combustíveis alternativos como os pneus inservíveis, podem ser fontes permanentes não declaradas de contaminações ambientais e do próprio cimento produzido.

\section{O CIMENTO PORTLAND}

Em 1824, o construtor inglês Joseph Aspdin calcinou pedras calcárias com argila, transformando-as em um pó fino. Percebeu que obtinha uma mistura que, após secar, tornava-se tão dura quanto às pedras empregadas nas construções. A mistura foi então patenteada no mesmo ano com o nome de cimento portland e, recebeu esse nome por apresentar propriedades semelhantes às rochas da ilha britânica de Portland (BASÍLIO, 1983). É constituído de um pó fino de tamanho aproximado de $50 \mu \mathrm{m}$, resultante de uma mistura formada pelo clínquer $(96 \%)$ e, outras substâncias, tais como, o gesso $(4 \%)$ e escórias de silício, que dependendo das características desejadas para o cimento, são adicionadas em certas quantidades.

O cimento é um material de propriedades adesivas, cerâmico que, em contacto com a água, produz uma reação exotérmica de cristalização de produtos hidratados, ganhando assim, resistência mecânica (TAYLOR, 1992).

O clínquer é produzido a partir da transformação térmica em fornos giratórios a elevadas temperaturas, de um material rochoso contendo, normalmente, $80 \%$ de carbonato de cálcio $\left(\mathrm{CaCO}_{3}\right), 15 \%$ de dióxido de silício $\left(\mathrm{SiO}_{2}\right), 3 \%$ de óxido de alumínio $\left(\mathrm{Al}_{2} \mathrm{O}_{3}\right)$ e, quantidades menores de outros constituintes como o ferro, o enxofre e outros. A composição química percentual, sob forma de óxidos, de um cimento pode ser apresentada na tabela 1, a seguir:

Tabela 1 - Composição química de um cimento

\begin{tabular}{|c|c|}
\hline Composição química & \% massa \\
\hline $\mathrm{CaO}$ & $58,9-66,8$ \\
\hline $\mathrm{SiO}_{2}$ & $19,0-24,2$ \\
\hline $\mathrm{Al}_{2} \mathrm{O}_{3}$ & $3,9-7,3$ \\
\hline $\mathrm{Fe}_{2} \mathrm{O}_{3}$ & $1,8-5,0$ \\
\hline $\mathrm{MgO}$ & $0,8-6,0$ \\
\hline $\mathrm{SO}_{3}$ & $0,9-3,0$ \\
\hline
\end{tabular}

As instalações utilizadas para produção de clínquer, geralmente, baseiam-se na existência central de um forno rotativo cilíndrico colocado em posição horizontal, porém, com uma ligeira inclinação onde circulam os gases de aquecimento resultantes da queima de um combustível em contracorrente com a matéria-prima para produção do clínquer, conforme mostra, a seguir, a figura 1 .

Além disso, o forno de clínquer sofre uma baixa rotação empurrando a matéria-prima que entra na parte mais elevada para a extremidade inferior, já na forma de clínquer. Já o combustível utilizado é fornecido e queimado na parte mais baixa e, em contracorrente com a matéria-prima até a extremidade oposta.

Os fornos de clínquer são revestidos com material refratário compatível com a massa fluida do clínquer, visando minimizar a perda de calor para o exterior, permitindo, assim, que a temperatura no interior do forno atinja temperaturas de até $2000{ }^{\circ} \mathrm{C}$ (TAYLOR, 1992). 

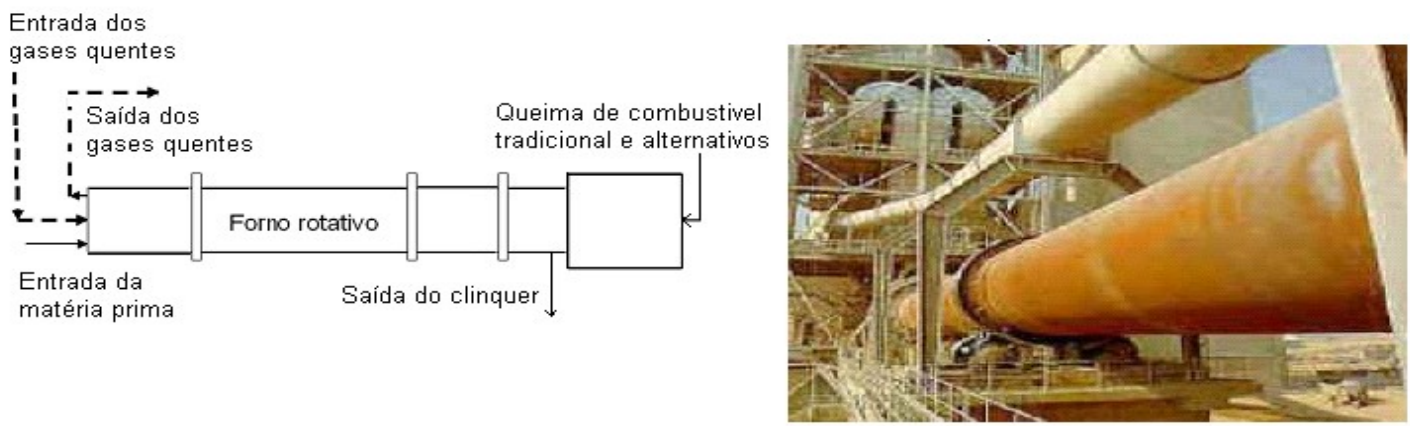

Figura1 - Esquema e vista geral de um forno rotativo

A energia necessária à secagem, calcinação e a sinterização do clínquer são obtidas pela queima de uma variedade de combustíveis, dos quais os mais comumente empregados são: o carvão mineral, gás natural e óleo combustível. Entretanto, na política de economia energética são utilizados combustíveis alternativos provenientes de resíduos de diversas indústrias (desde que alcancem um poder calorífico aceitável), tais como: petróleo/petroquímica, papéis, plásticos, tintas, pneus inservíveis e, muitos outros.

Ao se utilizar esses resíduos, além dos elementos maiores como o cálcio, silício, ferro e alumínio, outros elementos são introduzidos com os combustíveis, tais como, magnésio, enxofre, sódio, potássio, manganês, fósforo e titânio, elementos traços como cromo, chumbo, zinco, vanádio, níquel e muitos outros (BASÍLIO, 1983).

As primeiras queimas de resíduos clorados em fornos de produção de clínquer foram realizadas nos anos 70, no Canadá. Na Europa, a França realizou testes em 1978 e, a Suécia incinerou, também, resíduos clorados (KIHARA, 1999). Os Estados Unidos iniciaram suas atividades de queima de resíduos industriais, em fornos de cimenteiras, em 1979, (MOORE, 1995).

Segundo estimativas OFICEMEN (1998), no ano de 1997, foram processadas, na Europa mais de $400.000 \mathrm{t}$ de pneus nos fornos de clínquer das fábricas de cimento.
No Japão, segundo Uchikawa (1992), na década de 90, foram queimados 26 tipos de resíduos industriais, dentre os pneus inservíveis, como substitutos de combustível, correspondendo a uma economia de 110.000 t de carvão.

\section{PRINCIPAIS REAÇÕES QUÍMICAS NO PROCESSO DE CLINQUERIZAÇÃO}

As principais reações que fazem parte do processo de cliquerização, com base em Taylor (1997) e Hewlett (2003), são as seguintes:

\subsection{EVAPORAÇÃO DA ÁGUA LIVRE}

$\mathrm{H}_{2} \mathrm{O}(\mathrm{l}) \rightarrow \mathrm{H}_{2} \mathrm{O}(\mathrm{v}) \quad \Delta \mathrm{H}=-539,6 \mathrm{cal} / \mathrm{g}$

3.2 Decomposição do carbonato de magnésio

$\mathrm{MgCO}_{3}(\mathrm{~s}) \rightarrow \mathrm{MgO}(\mathrm{s})+\mathrm{CO}_{2}(\mathrm{~g})$

$\Delta \mathrm{H}=-270 \mathrm{cal} / \mathrm{g}$

3.3 Decomposição do carbonato de cálcio

$$
\begin{gathered}
\mathrm{CaCO}_{3}(\mathrm{~s}) \rightarrow \mathrm{CaO}(\mathrm{s})+\mathrm{CO}_{2}(\mathrm{~g}) \\
\Delta \mathrm{H}=-393 \mathrm{cal} / \mathrm{g}\left(805-894^{\circ} \mathrm{C}\right)
\end{gathered}
$$

Por ordem de seqüência no processo industrial, inicialmente, é evaporada a água presente, juntamente com outros materiais voláteis. Entre temperaturas de $500-900^{\circ} \mathrm{C}$ procede-se a descarbonatação do material calcário, que consiste na calcinação, com produção de óxido de cálcio $(\mathrm{CaO})$ para o clínquer e liberação de dióxido de carbono $\left(\mathrm{CO}_{2}\right)$ para a atmosfera. 
Em temperaturas entre 850 e $1250^{\circ} \mathrm{C}$ dá-se à sinterização que é a reação entre o óxido de cálcio e as substâncias sílico-aluminosas com formação do produto final, os aluminatos tri-cálcicos $\quad\left(3 \mathrm{CaO} . \mathrm{Al}_{2} \mathrm{O}_{3}\right)$ e os compostos de ferro aluminatos tetra clínquer, constituídos por silicatos dicálcicos $\quad\left(2 \mathrm{CaO} . \mathrm{SiO}_{2}\right)$ e, ferroaluminato-tetra-cálcicos

$\left(4 \mathrm{CaO} \cdot \mathrm{Al}_{2} \mathrm{O}_{3} \cdot \mathrm{Fe}_{2} \mathrm{O}_{3}\right)$ onde a temperatura de saída do clínquer pode atingir $2.000^{\circ} \mathrm{C}$ (BASÍLIO, 1983).

\section{A QUEIMA DE PNEUS INSERVÍVEIS}

Em 1839, Goodyear descobriu por acaso, o tratamento da borracha natural (vulcanização), na qual a mistura de borracha com enxofre que, ao ser derramada ao fogo quente, ficava mais elástica $\mathrm{e}$, percebeu que a borracha carbonizada, mesmo depois de congelada, não mudava suas características.

Graças a este experimento, a humanidade tem, através dos anos, desfrutado de um útil e necessário invento, o pneu, que proporciona desempenho, economia e conforto útil, ao funcionamento de veículos terrestres, automotores, utilitários como bicicletas, tratores, máquinas agrícolas, caminhões, etc., pois, acredita-se que a produção mundial de pneus esteja da ordem de um bilhão de unidades (ANIP, 2004)

Entretanto, os pneus velhos, inservíveis, espalhados, dentro e fora das lixeiras, constituem um perigo ambiental sob vários aspectos, sendo, no entanto, classificados na lista européia de resíduos, como um resíduo não perigoso. É importante declarar, que os depósitos de pneus abandonados constituem uma bomba, caso haja a possibilidade de incêndios (CAPONERO, 2000).

O enxofre é uma matéria prima utilizada em vários segmentos industriais, pode ser proveniente de várias origens, tais como: depósitos geológicos de enxofre elementar removidos pelo processo Frasch; recuperação de enxofre de sulfetos metálicos e recuperação pelo processo Claus de enxofre proveniente de sulfeto de hidrogênio procedentes de gás natural ou de refinarias de petróleo (MAINIER \& ROCHA, 2003).

Do ponto de vista de contaminações naturais, geralmente, os minérios de arsênio, geralmente, sob a forma de sulfeto arsenioso $\left(\mathrm{As}_{2} \mathrm{~S}_{3}\right)$, encontram-se associados aos minérios sulfetados $\left(\mathrm{FeS}_{2}, \mathrm{PbS}, \mathrm{CuS}\right.$ e $\left.\mathrm{ZnS}\right)$.

$\mathrm{O}$ processamento industrial de recuperação de enxofre e metais como o cobre, o zinco e o chumbo constam essencialmente, da oxidação e redução, conforme mostram as reações, a seguir:

$$
\begin{aligned}
& \mathrm{ZnS}+\mathrm{O}_{2} \rightarrow \mathrm{ZnO}+\mathrm{SO}_{2} \quad\left(1200^{\circ} \mathrm{C}\right) \\
& 2 \mathrm{ZnO}+\mathrm{C} \rightarrow 2 \mathrm{Zn}+\mathrm{CO}_{2}\left(1100^{\circ} \mathrm{C}\right) \\
& \mathrm{SO}_{2}+\mathrm{C} \rightarrow \mathrm{S}+\mathrm{CO}_{2} \quad\left(1100^{\circ} \mathrm{C}\right)
\end{aligned}
$$

Da mesma forma, o sulfeto arsenioso $\left(\mathrm{As}_{2} \mathrm{~S}_{3}\right)$ associado ao minério de zinco pode reagir, formando o arsênio e incorporando-se ao enxofre produzido conforme mostra a reação, a seguir. A contaminação é aleatória, pois, depende do teor de arsênio no minério.

$$
\begin{aligned}
& \mathrm{As}_{2} \mathrm{~S}_{3}+9 / 2 \mathrm{O}_{2} \rightarrow \mathrm{As}_{2} \mathrm{O}_{3}+3 \mathrm{SO}_{2}\left(1200^{\circ} \mathrm{C}\right) \\
& 2 \mathrm{As}_{2} \mathrm{O}_{3}+3 \mathrm{C} \rightarrow 4 \mathrm{As}+3 \mathrm{CO}_{2}\left(1100^{\circ} \mathrm{C}\right)
\end{aligned}
$$

Por outro lado, é muito pouco provável a contaminação com arsênio quando o enxofre é obtido partir de depósitos geológicos ou quando é produzido a partir de sulfeto de hidrogênio $\left(\mathrm{H}_{2} \mathrm{~S}\right)$ existente no gás natural.

Atualmente, o preço médio do enxofre é de 65 a 70 dólares por tonelada, embora este preço, vá depender da utilização industrial, da pureza, da origem e/ou do processamento industrial. Para lotes de enxofre contaminado, o preço é reduzido em valores de 20 a $40 \%$.

Por motivos técnicos, ou normas de especificação, o enxofre contaminado com arsênio não pode ser empregado na fabricação de ácido sulfúrico, fertilizante 
e outros compostos químicos de indústria de base, entretanto, na vulcanização de borracha para pneus não foi encontrada nenhuma restrição.

A queima de pneus em fornos de cimenteiras consiste no simples processo de introduzir e adicionar resíduos à carga que vai alimentar o forno para queima, no entanto, essa prática pode ser desastrosa considerando-se que o processo de queima é realizado em contra corrente, ou seja, a carga vai sendo aquecida, progressivamente, antes de chegar à zona de combustão. Dependendo da velocidade de queima, as substâncias voláteis podem ser arrastadas antes de atingirem a temperatura necessária à sua destruição.

O monóxido de carbono ( $\mathrm{CO}$ ) e COV (compostos orgânicos voláteis) poderão ocorrer, principalmente, em casos em que se efetue um fornecimento de combustível não totalmente controlado e/ou em que há uma mistura pouco eficaz com o ar comburente, originando uma deficiência de oxigênio.

Dessa forma, segundo Santi (2004), a queima de pneus, ou de qualquer outro resíduo em fornos de cimento, deve seguir alguns critérios estabelecidos pelos órgãos ambientais responsáveis do local onde as cimenteiras estão instaladas.

Visando quantificar a queima de pneus pode-se adotar uma composição média dos constituintes conforme mostra a tabela 2 , a seguir.

Tabela 2 - Composição química de pneus

\begin{tabular}{|c|c|}
\hline Composição química & \% massa \\
\hline Carbono & 70,0 \\
\hline Hidrogênio & 7,0 \\
\hline Óxido de zinco & 1,2 \\
\hline Enxofre & 1,3 \\
\hline Ferro & 15,0 \\
\hline Outros & 5,5 \\
\hline \multicolumn{2}{|l}{}
\end{tabular}

Com base na composição química média de um pneu, apresentada na tabela 2, a queima total (oxidação total) de uma tonelada de pneus pode significar, teoricamente, uma emissão 2,56 t de $\mathrm{CO}_{2}$ e $26 \mathrm{~kg}$ de $\mathrm{SO}_{2}$ para atmosfera.

Caso o enxofre contido em uma tonelada de pneu tenha, respectivamente, $0,1 \%, 0,5 \%$ e $1 \%$, a emissão para a atmosfera de óxido arsenioso $\left(\mathrm{As}_{2} \mathrm{O}_{3}\right)$ será de $17 \mathrm{~g}, 85 \mathrm{~g}$ e $170 \mathrm{~g}$. Esses valores são dificilmente identificados e quantificados na emissão dos gases quentes para atmosfera, entretanto, no momento em que se multiplicam pelo valor da produção anual, a massa de óxido, então, torna-se significativa.

Ensaios laboratoriais realizados com a queima de amostras de borracha vulcanizada com enxofre de alta pureza e enxofre contaminados com arsênio, em temperatura da ordem de $500^{\circ} \mathrm{C}$, confirmaram a formação de óxido arsenioso $\left(\mathrm{As}_{2} \mathrm{O}_{3}\right)$ diluído na massa gasosa, juntamente com o dióxido de carbono $\left(\mathrm{CO}_{2}\right)$ e o dióxido de enxofre $\left(\mathrm{SO}_{2}\right)$.

\section{CONSIDERAÇÕES E CONCLUSÕES FINAIS}

Os países desenvolvidos tentam vender a idéia de lucro ao se incinerar pneus em lugar de combustíveis convencionais, visando uma forma de se "livrar" desse incômodo ambiental junto aos países em desenvolvimento. Essa colocação deve-se ao fato, de que por mais que se incinerem pneus, a massa de pneus inservíveis cresce numa progressão muito acima daquela que se pode queimar nos fornos industriais (GÜNTHER, 2000).

Existe um grande inconveniente, em termos ambientais, no que diz respeito à emissão de grandes quantidades de $\mathrm{SO}_{\mathrm{x}}$, quando são incinerados pneus em fornos de cimenteiras.

Além disso, a possibilidade de contaminações com arsênio e outros contaminantes podem caracterizar um problema ambiental. Entretanto, considerando a grande quantidade de ar 
que entram nos queimadores, os contaminantes que saem nos gases quentes tornam-se desprezíveis.

$\mathrm{Na}$ visão crítica só tornam-se significativos quando são quantificados em produção atual.

Deve-se acautelar quanto aos riscos acrescidos ao nível das localizações no qual, o processo de tratamento de resíduos em coincineração ocorre, através da prévia caracterização detalhada das condições ambientais e populacionais de cada local em causa e, das posteriores monitoração ambiental e vigilância epidemiológica.

Os procedimentos acima citados constituem os recursos sustentáveis para prevenir, garantir a detecção precoce de complicações e, minimizar ou eliminar eventuais riscos.

No âmbito da educação ambiental, a fabricação do cimento, da mesma forma que outros processos de produção de outros produtos, têm sua forma de abordagem quase ingênua e, nos cursos de graduação nos quais são apresentadas, não são enfatizados os problemas ambientais acima descritos e, nem propostas soluções alternativas de processo, a fim de minimizar, ou mesmo eliminar, os riscos que envolvem sua produção.

\section{REFERÊNCIAS}

ABCP, Associação Brasileira de Cimento Portland, III Encontro da ANPPAS, 2004.

BASÍlLIO, F. A., Cimento Portland, Estudo Técnico, ABCP, $5^{\mathrm{a}}$ edição, São Paulo, 1983.

CAPONERO, J. \& TENÓRIO, J. A. S., 2000 , Study of the pyrolisis reactors of brazilian waste tire using TGA and DTA. Department de Engenharia Metalurgica e de Materiais, U.S.P. São Paulo, 1983.

GÜNTHER, W. M. R., Minimização de resíduos e educação ambiental. VII Seminário Nacional de Resíduos Sólidos e Limpeza Pública, ABPL, Associação Brasileira de Limpeza Pública, SP, 2000.

HEWLETT, P. C., Lea's chemistry cement and concrete, England: Butterwort Heinemann, 2003

KIHARA, Y., Impacto da normalização do co-processamento de resíduos em fornos de clínquer, Congresso Brasileiro de Cimento, São Paulo, 1999.

MAINIER, F. B. \& ROCHA, A. A., $\mathrm{H}_{2} \mathrm{~S}$ : Novas rotas de remoção química e recuperação de enxofre In: Anais $2^{\circ}$ Congresso Brasileiro de P\& D em Petróleo \& Gás, Hotel Glória, UFRJ, Rio de Janeiro, 2003, 6p.

MOORE, T. E., Co-processamento de insumos alternativos In: Ciclo de Conferências: Indústria de cimento, fabricação, co-processamento e meio ambiente, FEEMA, Rio de Janeiro, Anais, 1995, p.127-151.

OFICEMEN, Agrupación de Fabricantes de Concreto de España. Combustibles alternativos en la fabricación del cemento, Madrid, 1998, 26p.

SANTI, A. M. M., Co-incineração e coprocessamento de resíduos industriais perigosos em fornos de clínquer; investigação do maior pólo produtor de cimento do país. Região metropolitana de Belo Horizonte, MG. Tese de doutorado, Campinas, 2003

TAYLOR, H. F. W., Cement Chemistry, $2^{\mathrm{a}}$ ed., London, Academic Press, 1992

UCHIKAWA， H., $9^{\text {th }}$ International congress of cement held in New Deli, 1992 